\title{
Effects of silica coating and silane surface conditioning on the bond strength of rebonded metal and ceramic brackets
}

\author{
Saadet ATSÜ1', Bülent ÇATALBAŞ², İbrahim Erhan GELGÖR ${ }^{3}$ \\ 1- DDS, PhD, Associate Professor, Prosthetic Dentistry, Faculty of Dentistry, Kirikkale University, Kirikkale, Turkey. \\ 2- DDS, PhD, Assistant Professor, Department of Orthodontics, Faculty of Dentistry, Kirikkale University, Kirikkale, Turkey. \\ 3- DDS, PhD, Associate Professor, Department of Orthodontics, Faculty of Dentistry, Kirikkale University, Kirikkale, Turkey.
}

Corresponding address: Dr. Saadet Atsü - Prosthetic Department, School of Dentistry, Kirikkale University, - Mimar Sinan Cad, No: 25 - Dishekimligi Fakultesi - Kirikkale - Merkez - 71100 - Turkey - e-mail: saadetats@yahoo.com

Received: August 28, 2009 - Modification: February 19, 2010 - Accepted: April 29, 2010

\section{ABSTRACT}

\begin{abstract}
O bjective: The aim of this study was to evaluate the effects of tribochemical silica coating and silane surface conditioning on the bond strength of rebonded metal and ceramic brackets. Material and Methods: Twenty debonded metal and 20 debonded ceramic brackets were randomly assigned to receive one of the following surface treatments ( $n=10$ for each group): (1) sandblasting (control); (2) tribochemical silica coating combined with silane. Brackets were rebonded to the enamel surface on the labial and lingual sides of premolars with a light-polymerized resin composite. All specimens were stored in distilled water for 1 week and then thermocycled $\left(5,000\right.$ cycles) between $5-55^{\circ} \mathrm{C}$. Shear bond strength values were measured using a universal testing machine. Student's t-test was used to compare the data $(\alpha=0.05)$. Failure mode was assessed using a stereomicroscope, and the treated and non-treated bracket surfaces were observed by scanning electron microscopy. Results: Rebonded ceramic brackets treated with silica coating followed by silanization had significantly greater bond strength values $(17.7 \pm 4.4 \mathrm{MPa})$ than the sandblasting group $(2.4 \pm 0.8 \mathrm{MPa}, \mathrm{P}<0.001)$. No significant difference was observed between the rebonded metal brackets treated with silica coating with silanization $(15 \pm 3.9 \mathrm{MPa})$ and the sandblasted brackets $(13.6 \pm 3.9 \mathrm{MPa})$. Treated rebonded ceramic specimens primarily exhibited cohesive failure in resin and adhesive failure at the enamel-adhesive interface. Conclusions: In comparison to sandblasting, silica coating with aluminum trioxide particles followed by silanization resulted in higher bond strengths of rebonded ceramic brackets.
\end{abstract}

Key words: Orthodontic brackets. Bond. Shear strength. Silanes.

\section{INTRODUCTION}

Loose or inaccurately placed brackets that require repositioning during treatment are a common complication faced by orthodontists. For a variety of reasons, clinical bond failure occurs in 5 to $7 \%$ of brackets bonded with light-cured or chemicalcured resin composite $e^{4,8,16,26}$. As a result, a significant number of teeth must be rebonded in orthodontic practice ${ }^{4}$. Re-use of a debonded bracket is practical and lowers costs, making rebonding a common procedure in orthodontic treatment ${ }^{4,11,21,22}$. However, any distortion of the bracket base or change in slot size that occurs during bracket reconditioning may reduce bracket bond strength and the efficacy of orthodontic treatment. The bond strength of a recycled bracket may also be less than that of a new bracket if the bracket base is not properly treated 7,8 .

Several chairside methods are available for bracket reconditioning. Resin composite may be cleaned from debonded brackets by stoning with green stones, burning with a Bunsen flame (3 s), sandblasting, or electropolishing (20 s $)^{4,11,21,22}$. Sandblasting with aluminum oxide particles also creates a slight roughness that increases the surface area, thereby enhancing mechanical and chemical bonding ${ }^{18}$. However, the use of sandblasting alone may not be enough to obtain reliable bond strength, 
especially after thermocycling ${ }^{12}$. Advances in silane coupling agents have contributed to high bond strength by promoting a chemical bond between resin composite, ceramic (silica-based) and metal (base metal) 3,5,19.

Tribochemical silica coating provides ultrafine mechanical retention and is used in conjunction with a silane coupling agent ${ }^{3,17}$. With this technique, metal or ceramic surfaces are abraded with CoJetSand (3M ESPE AG, Seefeld, Germany), a 30- $\mu$ mgrained aluminum oxide $\left(\mathrm{Al}_{2} \mathrm{O}_{3}\right)$ chemically modified with silica, using an intraoral sandblaster ${ }^{3,18,27}$. Not only is the surface abraded; it acquires a silica coating derived from the silica-coated aluminum trioxide particles used in abrasion. The technique of silica coating has many applications in dentistry and has been shown to increase the bond strength of aluminum and zirconium oxide ceramics to resin composite and of metal and ceramic brackets to enamel2,3,18,27,30. Nevertheless, little information is available regarding the effects of silica coating followed by silanization on the bond strength of recycled metal and ceramic brackets.

The aim of this study was to evaluate the effects of tribochemical silica coating and a silane coupling agent on the bond strength of recycled metal and ceramic brackets. The null hypothesis tested was that tribochemical silica coating and silane agent treatment increase the bond strength of rebonded metal and ceramic brackets.

\section{MATERIAL AND METHODS}

The study was conducted with 20 freshly extracted human caries-free, restoration-free maxillary premolars. Teeth were cleaned of residual organic material, and the labial and lingual surfaces were polished with flour of pumice using a rubber cup, rinsed with tap water and dried with an air-syringe ${ }^{2}$. Debonded brackets were obtained as described in previous studies ${ }^{7,25}$. Metal $(n=20)$ (Generus-Roth, stainless steel, \#B577; GAC International, Bohemia, NY, USA) and ceramic $(n=20)$ (Allure, 99.9\% pure alumina, \#2530013; GAC International, Bohemia, NY, USA) maxillary premolar brackets were bonded to unetched, damp tooth surfaces using light-polymerized Bis-GMA resin composite luting cement (Light Bond, \#402270; Reliance Orthodontic Products, Itasca IL, USA) polymerized using a fast halogen light curing unit (Hilux 250, First Medica, Greensboro, NC, USA, light intensity of $600 \mathrm{mw} /$ $\mathrm{cm}^{2}$ ). Brackets were manually placed using bracket pliers, and excess resin was removed from the bracket periphery prior to polymerization. The luting resin was light-polymerized for a total of $30 s-10$ $\mathrm{s}$ over the bracket face and $20 \mathrm{~s}$ interproximally (10 s mesially, $10 \mathrm{~s}$ distally). The bonded brackets were then separated from the tooth surfaces using a sharp-edged bracket-removal pliers (I00579; Rocky Mountain Orthodontics, Denver, CO, USA) 7,25 .

The debonded metal and ceramic brackets were randomly assigned to different groups to receive the following surface treatments ( $n=10$ for each group): (1) sandblasting with $50-\mu \mathrm{m}$ aluminum oxide (SB) (control); (2) airborne particle abrasion with $30 \mu \mathrm{m}$ aluminum trioxide particles modified by silica+silane (SCS). Sandblasting was performed with 50- $\mu \mathrm{m}$ aluminum oxide (Dentsply GAC, \#73613; NY, USA) using an intraoral sandblaster (Microetcher II, Danville Engineering, San Ramon, CA, USA) at 65 psi for 7-12 s until bonding resin was no longer visible to the naked eye. Each sandblasted bracket base was then rinsed with water for $5 \mathrm{~s}$ and dried with an air spray $7,20,24$. Prior to rebonding, the debonded brackets were visually reinspected ${ }^{8,11,20,22,24}$, and if any remaining resin was observed on the bracket surfaces, sandblasting, rinsing and air-drying was repeated as described above. Silica coating was performed with $30 \mu \mathrm{m}$ silicon dioxide (CoJet Sand, \#267044; 3M ESPE AG, Seefeld, Germany) using an intraoral sandblaster (Microetcher II, Danville Engineering). In accordance with the manufacturer's instructions, abrasion was performed vertically to the bracket surfaces at a distance of $10 \mathrm{~mm}$ with $0.25 \mathrm{MPa}$ pressure for $15 \mathrm{~s}$. Residual coating agents were removed using a stream of dry, oil-free air. One coat of silane (ESPE-Sil AG, \#265030; Seefeld,) was applied to conditioned specimens using a clean brush and was allowed to air-dry for $5 \mathrm{~min}$ in accordance with the manufacturer's recommendations.

Brackets were rebonded to the same premolar teeth from which they were debonded. Any residual adhesive remaining on labial and lingual surfaces after debonding was removed with a finishing carbide bur (Komet, \#047523, Lemgo, Germany) until the enamel surface regained its gloss ${ }^{4}$. Teeth were then polished with flour of pumice and a rubber cup, rinsed with tap water, and dried with an airsyringe. Labial and lingual surfaces were etched for 15 s with $35 \%$ phosphoric acid (Dentsply CAULK, \# 070910), rinsed for $20 \mathrm{~s}$ and air-dried for $5 \mathrm{~s}$ with oil-free $a^{2}{ }^{2}$. Rebonding was performed by applying a thin layer of a Bis-GMA bonding agent (Light Bond, \#403100; Reliance Orthodontic Products). Excess resin was removed with an air-syringe, and the bonding agent was cured using a fast halogen light curing unit (Hilux 250, First Medica, Greensboro, NC, light intensity of $600 \mathrm{mw} / \mathrm{cm}^{2}$ ) for $20 \mathrm{~s}$, according to the manufacturer's instructions. Brackets were then rebonded to the enamel surfaces with light-polymerized Bis-GMA resin composite luting cement (Light Bond, \#402270; Reliance Orthodontic Products). Brackets were manually placed using bracket pliers, and excess resin was removed with an air-syringe from the bracket periphery prior to polymerization. The luting resin 
was light-polymerized for a total of 30 s - 10 s over the bracket face and $20 \mathrm{~s}$ interproximally (10 s mesially, $10 \mathrm{~s}$ distally). In the bonding and rebonding procedure, all brackets were cemented by the same investigator using to as great extent as possible the same pressure, according to the manufacturer's instructions $2,4,7,8,10,11,25$.

Test specimens were stored in distilled water at $37^{\circ} \mathrm{C}$ for 1 week, thermocycled using a custom-made thermocycling device (Ankara University, Ankara, Turkey) for 5,000 cycles between $5^{\circ} \mathrm{C}$ and $55^{\circ} \mathrm{C}$, with a transfer time of $30 \mathrm{~s}$ and a dwell time of $30 \mathrm{~s}$. Following thermocycling, specimens were embedded in autopolymerizing clear acrylic resin (Meliodent, \#013013; Heraus, Kulzer, Dormagen, Germany) and mounted in a universal testing machine (Lloyd LRX; Lloyd Instruments Ltd, Fareham, UK). An occlusogingival load was applied to each specimen using a knife-edge blade at a crosshead speed of $0.5 \mathrm{~mm} /$ min until failure, with the test assembly adjusted to ensure that the shear force was directed at the bracket-tooth interface, not at the bracket itself. The surface area of the bracket base was calculated by measuring the length and width of each bracket base with a digital caliper (Model CD-15CPX, Mitutoyo, Tokyo, Japan) and computing the mean area (12.69 $\mathrm{mm}^{2}$ for both metal and ceramic brackets). Bond strength was derived by dividing the failure load $(\mathrm{N})$ by the bonding area $\left(\mathrm{mm}^{2}\right)$ and was expressed in MPa.

Debonded specimens were examined under a stereomicroscope (Leica MZ 12, Leica Microsystems, Bensheim, Germany) at x80 magnification by the same operator to assess the mode of failure, as represented by adhesive remnant index (ARI) value, according to the following criteria $^{1}$ : 0 , no adhesive left on the tooth; 1 , less than half of the adhesive left on the tooth; 2, more than half of the adhesive left on the tooth; and 3, all adhesive left on the tooth. Following this, 1 specimen from each group was sputter-coated with a gold-palladium alloy (Hummer VII; Anatech Ltd, Alexandria, VA, USA) and examined under a scanning electron microscope
(SEM) (JSM-5600; JEOL Ltd, Tokyo, Japan) at x100 and $\times 200$ magnification to observe the topographic patterns. Statistical analysis was performed using the statistical software package SPSS 12.0 (SPSS Inc., Chicago, IL, USA). Mean shear bond strengths of groups was compared using Student's t-test, and differences in ARI scores between groups were assessed using the Chi-square test (with scores combined as ARI 0-1 and ARI 2-3). Significance for all statistical tests was set at $P<0.05$.

\section{RESULTS}

Mean bond strengths and standard deviations for each group are given in Table 1 . The mean shear bond strength of the ceramic SCS group (17.7 \pm 4.4 $\mathrm{MPa}$ ) was significantly higher than that of the ceramic SB group (2.4 $0.8 \mathrm{MPa})$. The mean shear bond strength of the metal SCS group ( $15 \pm 3.9 \mathrm{MPa})$ was also higher than that of the metal SB group $(13.6 \pm 3.9 \mathrm{MPa})$, but the difference between groups was not statistically significant $(P=0.44)$.

The distribution of failure modes, as expressed by ARI scores, is given in Table 2 . Rebonded metal brackets exhibited primarily cohesive failure in resin and mixed failure. Whereas all sandblasted ceramic specimens failed at the bracket-adhesive interface (100\% ARI-3), none of the siliconecoated specimens failed at the bracket-adhesive interface (0\% ARI-3). Enamel fractures were not observed in any of the specimens tested. Chi square test showed a statistical difference in ARI scores between the metal (Chi square value $=6.4, d f=1$, $\mathrm{P}=.01$ ) and ceramic (Chi square value $=10, \mathrm{df}=1$, $\mathrm{P}=.002$ ) bracket groups. SEM images of metal and ceramic bracket base surfaces are shown in Figures 1 and 2, respectively. Surface patterns of the metal SCS (Figure 1A), and SB (Figure 1B) specimens were similar; however, greater surface irregularity was observed in the ceramic SCS specimen when compared to the ceramic SB specimen (Figures 2A, B).

Table 1- Results of t-test for rebonded metal and ceramic brackets

\begin{tabular}{|c|c|c|c|c|c|c|}
\hline Groups & $\mathbf{N}$ & Mean & SD & $\mathbf{t}$ & df & $\mathbf{P}$ \\
\hline \multicolumn{7}{|l|}{ Metal brackets } \\
\hline \multirow[t]{2}{*}{ Sandblasting } & 10 & 13.6 & 3.9 & & & \\
\hline & & & & 0.79 & 18 & ns \\
\hline Tribochemical silica coating + silane & 10 & 15 & 3.9 & & & \\
\hline \multicolumn{7}{|l|}{ Ceramic brackets } \\
\hline \multirow[t]{2}{*}{ Sandblasting } & 10 & 2.4 & 0.8 & & & \\
\hline & & & & 10.84 & 18 & *** \\
\hline Tribochemical silica coating + silane & 10 & 17.7 & 4.4 & & & \\
\hline
\end{tabular}

ns indicates not significant; $S D=$ standard deviation ${ }^{* * *} \mathrm{P}<.001$ 
Table 2- Failure modes of groups according to $\mathrm{ARI}^{\mathrm{a}, \mathrm{b}}$

\begin{tabular}{lcccc}
\hline & \multicolumn{4}{c}{ ARI Index } \\
\hline Surface Treatment & 0 & 1 & 2 & 3 \\
& $\%(\mathrm{n})$ & $\%(\mathrm{n})$ & $\%(\mathrm{n})$ & $\%(\mathrm{n})$ \\
Metal brackets & & & & \\
Sandblasting & $10(1)$ & $50(5)$ & $10(1)$ & $30(3)$ \\
Tribochemical silica coating+silane & $10(1)$ & $60(6)$ & $10(1)$ & $20(2)$ \\
Ceramic brackets & & & & \\
Sandblasting & $0(0)$ & $0(0)$ & $0(0)$ & $100(10)$ \\
Tribochemical silica coating+silane & $20(2)$ & $80(8)$ & $0(0)$ & $0(0)$ \\
\hline
\end{tabular}

${ }^{\text {a }} \mathrm{ARI}$ indicates adhesive remnant index

${ }^{\mathrm{b}} \mathrm{ARI}$ : 0 , no composite left on tooth; 1 , less than half of composite left on tooth; 2 , more than half of composite left on tooth; 3 , all the composite on tooth

$\mathrm{n}$ : Number of groups (values in the brackets)
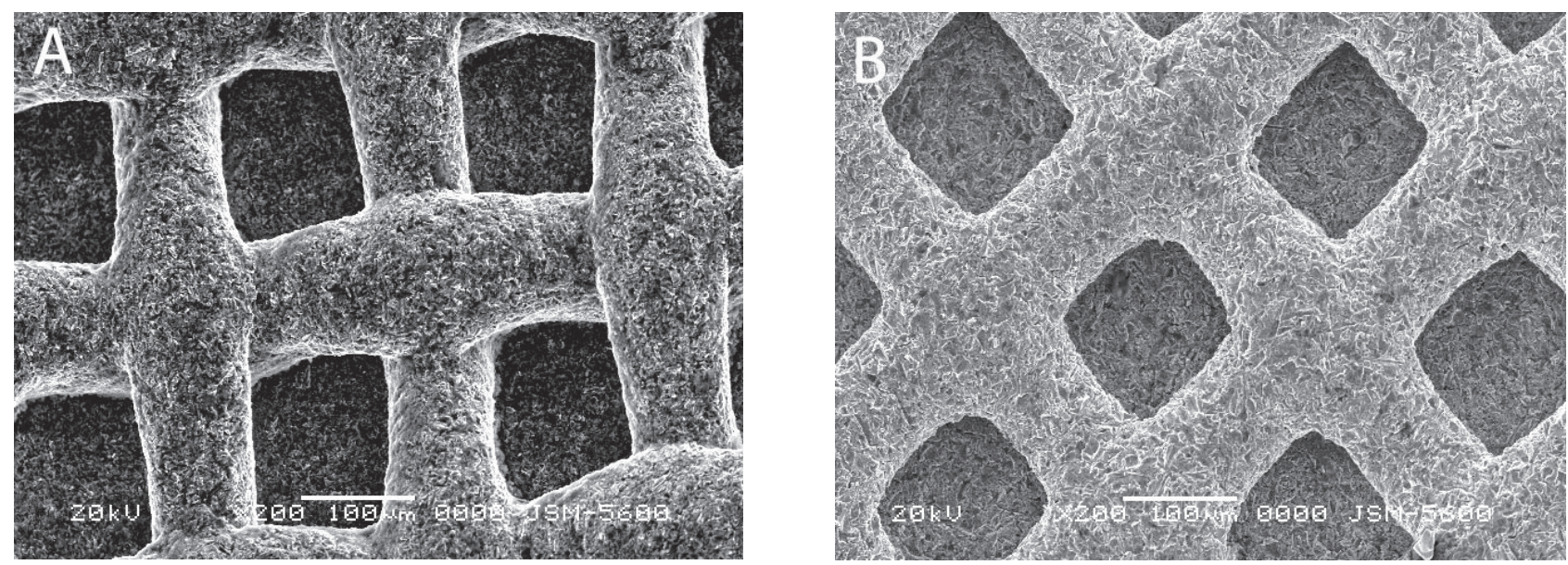

Figure 1- A, Scanning electron microscope (SEM) (original magnification x200) of the surface of a metal bracket airborne - particle abraded with 50- $\mu \mathrm{m} \mathrm{Al}_{2} \mathrm{O}_{3}$ (Group SB). B, SEM image (original magnification x200) of the surface of a metal bracket subjected to high-speed impaction with $30-\mu \mathrm{m} \mathrm{Al}_{2} \mathrm{O}_{3}$ modified by silica followed by silanization (Group SCS). Note the similar surface textures of $A$ and $B$
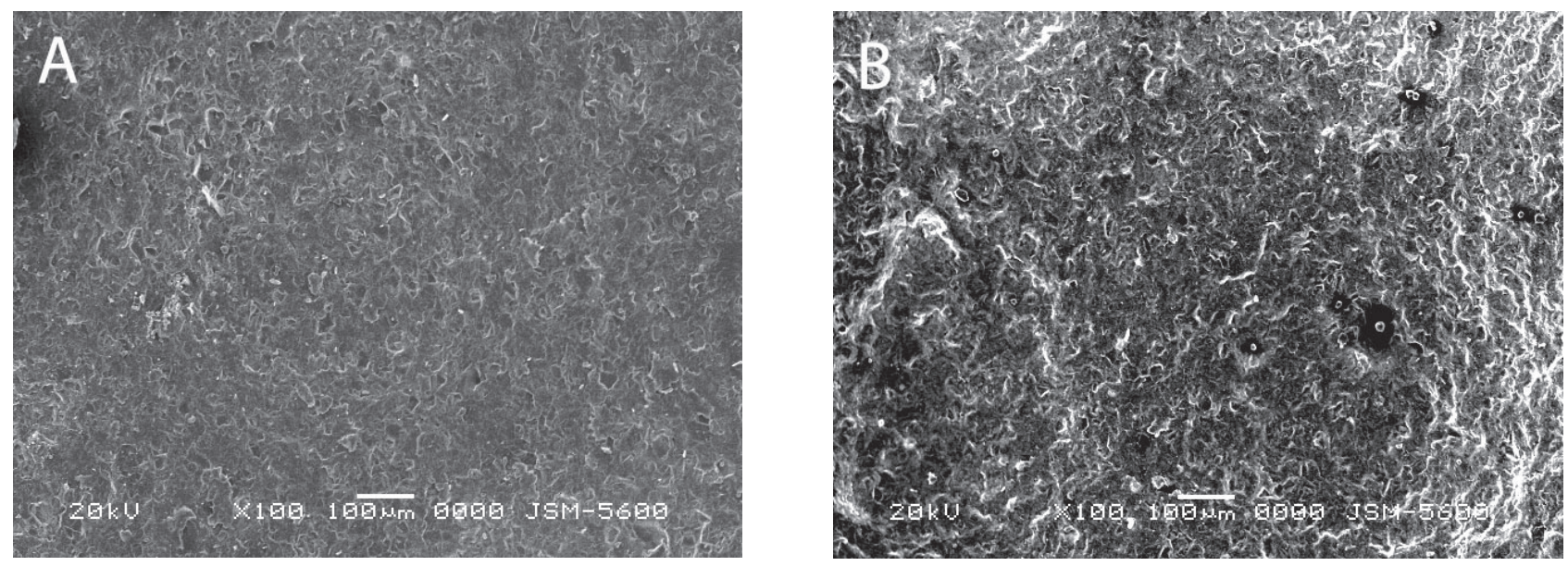

Figure 2- A, Scanning electron microscope (SEM) image (original magnification $\times 100$ ) of the surface of a ceramic bracket airborne- particle abraded with $50-\mu \mathrm{m} \mathrm{Al}_{2} \mathrm{O}_{3}$ (Group SB). B, SEM image (original magnification x100) of ceramic bracket surface subjected to high-speed surface impaction with $30-\mu \mathrm{m} \mathrm{Al}_{2} \mathrm{O}_{3}$ modified by silica followed by silanization (Group SCS). Note the greater irregularities on surface texture in $B$ 


\section{DISCUSSION}

Rebonding of ceramic and metal brackets is often required in orthodontic practice; however, limited data is available about the bond strength of rebonded brackets treated with different surface treatments. This study evaluated the effects of tribochemical silica coating and a silane coupling agent on the bond strength of recycled metal and ceramic brackets. The null hypothesis that tribochemical silica coating and silane treatment increases the bond strength of rebonded metal and ceramic brackets was partially confirmed. Silica coating followed by silanization resulted in higher bond strengths of rebonded ceramic brackets. Although silica coating and silane surface treatment slightly increased the bond strength of recycled metal brackets, a significant difference was not found.

In clinical practice, sandblasting of debonded bracket surfaces is frequently performed prior to rebonding them to enamel $8,20,22,24$. Not only does sandblasting remove any residual material from the restoration surface ${ }^{20}$, but also the rough surface produced as a result of sandblasting increases the surface area and wettability of the material, thereby enhancing mechanical and chemical bonding ${ }^{5,18}$.

With silica coating, the high-speed surface impact of the silica-modified aluminum particles used in airabrasion alter the surface of the debonded brackets, permitting micromechanical bonding between bracket and resin luting agent $3,23,27$. In addition, a chemical bond is formed between the silica-coated surface and the resin material ${ }^{30}$. Following silica coating, a silane agent is applied in a process known as silanization, which promotes adhesion between dissimilar materials. The trialkoxy silanes used in the process are comprised of the general formula $\mathrm{R}-\mathrm{Y}-\mathrm{SiX} 3$ (where $\mathrm{R}$ is a non-hydrolyzable organic group, e.g., methacrylate; $Y$, a linker; and $X$, the hydrolyzable group) and are polymerized with the resin composite to form chemical bonds ${ }^{14}$. The silane agent also contributes to improved surface wettability to resin ${ }^{19}$.

We found the bond strength of recycled ceramic brackets treated with a tribochemical silica coating

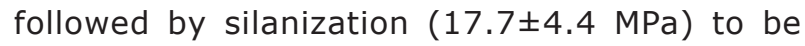
significantly higher than rebonded brackets treated by sandblasting $(2.4 \pm 0.8 \mathrm{MPa})$. This finding is in line with those of previous in vitro studies showing silane and/or silica coating treatment increased the bond strength of ceramic brackets ${ }^{2,8,25}$. Chung, et al. ${ }^{8}$ (2002) compared the bond strengths of new, rebonded/sandblasted and rebonded/sandblasted/ silane-treated ceramic brackets to enamel and found that the new brackets had the highest mean bond strength (15.6 MPa), followed by the rebonded/ sandblasted/silane-treated brackets (5.9 MPa) and the rebonded/sandblasted brackets (2.9 MPa). Toroğlu and Yaylali ${ }^{25}$ (2008) compared the effects of sandblasting, silica coating and silanization on the bond strengths of rebonded ceramic brackets and found the greatest improvements in bond strengths came from silica coating+silane (12.7 $\mathrm{MPa})$, followed by sandblasting+silane (10.5 MPa) and sandblasting alone (4.5 MPa).

In contrast to the findings for ceramic brackets, the present study showed silica coating and silane surface treatment did not significantly improve the bond strength of rebonded metal brackets, with the silica-coated and silane treated group demonstrating only a slightly higher bond strength (15 $\mathrm{MPa}$ ) than the sandblasted control group (13.6 $\mathrm{MPa}$ ). Although silica coating followed by silanization has been previously used to treat metal bracket surfaces $^{2}$, a literature review found no references to the effects of silica and silane surface treatment on the bond strength of recycled metal brackets to enamel. However, Tavares, et al.24 (2006) found sandblasting with $90-\mu \mathrm{m}$ aluminum oxide particles had no statistically significant affect on the bond strength of recycled metal brackets. Similarly, Grabouski, et al.11 (1998) found no significant differences among the mean bond strengths of new metal brackets and new and recycled metal brackets microetched with $50 \mu \mathrm{m}$ aluminum oxide particles to previously bonded teeth. In the present study, the bond strength of sandblasted recycled metal brackets was similar to that of metal brackets treated by silica coating, which creates a surface texture similar to that of sandblasting.

Successful orthodontic treatment depends on the adequate bond strength of brackets to enamel. Clinically, bond strength can be influenced by many environmental factors, including thermal changes. In general, the minimum bond strength required to withstand normal orthodontic forces is believed to be between 6-8 $\mathrm{MPa}^{6,10}$. This study showed that the mean shear bond strengths to enamel of thermocycled silicone-coated recycled metal and ceramic brackets exceeded these limits, as did thermocycled sandblasted recycled metal brackets; however, the mean shear bond strength of sandblasted recycled ceramic brackets was below this threshold. This indicates that the shear bond strengths of silica-coated/silane treated recycled ceramic and metal brackets and sandblasted recycled metal brackets are sufficient for clinical application.

Numerous other studies have used shear bond testing to evaluate the bond strength of brackets to enamel $2,4,6-8,10,11,13,22,24,25$. However, shear tests have been criticized for producing a nonhomogeneous distribution of stress on the bonded interface, resulting in either an underestimation or a misinterpretation of the test results stemming 
from the fact that failure often begins in one of the substrates rather than in the adhesive zone $e^{9,28,29}$. It is possible that the findings of previous research indicating that increased bond strength resulted in failure within the resin ${ }^{3,15,17}$ was affected by the test geometry ${ }^{28}$. This limitation should be taken into consideration when interpreting the results of shear tests.

In line with previous studies $3,15,17$, the silicacoated/silane treated ceramic specimens in our study exhibited cohesive failure within the resin and adhesive failure at the enamel-adhesive interface, but no cohesive failure within the enamel. ARI scores for the recycled metal brackets in our study primarily indicated cohesive failure within resin and mixed failure. SEM micrographs of the ceramic brackets revealed greater irregularities on the surface of the ceramic bracket-base of the silica-coated/silane-treated specimen when compared to the sandblasted specimen, whereas no significant differences in the surface texture of silica-coated/silane-treated and sandblasted metal specimens were observed. These findings are in line with the finding of differences in bond strength values between the silica-coated/silane-treated and sandblasted ceramic groups, but not between the silica-coated/silane-treated and sandblasted metal groups.

An important requirement in bracket bonding is that there should be no or minimal risk of iatrogenic damage to the enamel surface during debonding ${ }^{15}$. Although ceramic brackets are rigid and unyielding, no enamel fractures were observed during debonding in this study. Further investigations could be performed with the different orthodontic adhesives and tribochemical silica coating and silane surface conditioning. Clinician must consider cost effective and a less time-consuming method when choose rebonding of orthodontic brackets. Moreover, controlled clinical trials are needed before clinical recommendations can be provided.

\section{CONCLUSIONS}

Within the limitations of this study, the following conclusions were drawn:

1- Tribochemical silica coating followed by silanization significantly increased the mean bond strength of recycled ceramic brackets.

2- The bond strength of recycled metal brackets treated with tribochemical silica coating followed by silanization was slightly higher than sandblasted recycled metal brackets, but the difference in bond strengths was not statistically significant.

3- The bond strength of recycled metal and ceramic brackets treated with a tribochemical silica coating system was adequate for clinical use. In addition to being both economical and ecological, the use of recycled metallic and ceramic brackets can reduce chair time.

\section{REFERENCES}

1- Artun J, Bergland S. Clinical trials with crystal growth conditioning as an alternative to acid-etch enamel pretreatment. Am J Orthod. 1984;85:333-40.

2- Atsü SS, Gelgör IE, Sahin V. Effects of silica coating and silane surface conditioning on the bond strength of metal and ceramic brackets to enamel. Angle Orthod. 2006;76:857-62.

3- Atsü SS, Kilicarslan MA, Kucukesmen HC, Aka PS. Effect of zirconium oxide ceramic surface treatments on the bond strength to adhesive resin. J Prosthet Dent. 2006;95:430-6.

4- Bishara SE, VonWald L, Laffoon JF, Warren JJ. The effect of repeated bonding on the shear bond strength of a composite resin orthodontic adhesive. Angle Orthod. 2000;70:435-41.

5- Blatz MB, Sadan A, Kern M. Resin-ceramic bonding: a review of the literature. J Prosthet Dent. 2003;89:268-74.

6 - Bourke BM, Rock WP. Factors affecting the shear bond strength of orthodontic brackets to porcelain. Br J Orthod. 1999;26:285-90.

7- Chung $\mathrm{CH}$, Fadem BW, Levitt HL, Mante FK. Effects of two adhesion boosters on the shear bond strength of new and rebonded orthodontic brackets. Am J Orthod Dentofacial Orthop. 2000;118:295-9.

8- Chung CH, Friedman SD, Mante FK. Shear bond strength of rebonded mechanically retentive ceramic brackets. Am J Orthod Dentofacial Orthop. 2002;122:282-7.

9- Della Bona A, Van Noort R. Shear vs. tensile bond strength of resin composite bonded to ceramic. J Dent Res. 1995;74:1591-6. 10- Gillis I, Redlich M. The effect of different porcelain conditioning techniques on shear bond strength of stainless steel brackets. Am J Orthod Dentofacial Orthop. 1998;114:387-92.

11- Grabouski JK, Staley RN, Jakobsen JR. The effect of microetching on the bond strength of metal brackets when bonded to previously bonded teeth: an in vitro study. Am J Orthod Dentofacial Orthop. 1998;114:452-60.

12- Laufer BZ, Nicholls JI, Townsend JD. SiOx-C coating: a composite to metal bonding mechanism. J Prosthet Dent. 1988;60:320-7.

13- Lew KK, Chew CL, Lee KW. A comparison of shear bond strengths between new and recycled ceramic brackets. Eur J Orthod. 1991;13:306-10.

14- Matinlinna JP, Lassila LV, Ozcan M, Yli-Urpo A, Vallittu PK. An introduction to silanes and their clinical applications in dentistry. Int J Prosthodont. 2004;17:155-64.

15- Newman GV, Newman RA, Sun BI, Ha JJ, Ozsoylu SA. Adhesion promoters, their effect on the bond strength of metal brackets. Am J Orthod Dentofacial Orthop. 1995;108:237-41.

16- O'Brien KD, Read MJ, Sandison RJ, Roberts CT. A visible lightactivated direct-bonding material: an in vivo comparative study. Am J Orthod Dentofacial Orthop. 1989;95:348-51.

17- Özcan M. The use of chairside silica-coating for different dental applications: a clinical report. J Prosthet Dent. 2002;87:469-72. 18- Peutzfeldt A, Asmussen E. Silicoating: evaluation of a new method of bonding composite resin to metal. Scand J Dent Res. 1988;96:171-6.

19- Plueddemann PE. Nature of adhesion through silane coupling agents. New York: Plenum Press; 1982. p. 111.

20- Quick AN, Harris AM, Joseph VP. Office reconditioning of stainless steel orthodontic attachments. Eur J Orthod. 2005;27:231-6.

21- Regan D, LeMasney B, Van Noort R. The tensile bond strength of new and rebonded stainless steel orthodontic brackets. Eur J Orthod. 1993; 15:125-35.

22- Sonis AL. Air abrasion of failed bonded metal brackets: a study of shear bond strength and surface characteristics as determined by scanning electron microscopy. Am J Orthod Dentofacial Orthop. 1996;110:96-8. 
23- Sun R, Suanswan N, Kilpatrick N, Swain M. Characterisation of tribochemically assisted bonding of composite resin to porcelain and metal. J Dent. 2000;28:441-5.

24- Tavares SW, Consani S, Nouer DF, Magnani MB, Nouer PR, Martins LM. Shear bond strength of new and recycled brackets to enamel. Braz Dent J. 2006;17:44-8.

25- Toroğlu MS, Yaylali S. Effects of sandblasting and silica coating on the bond strength of rebonded mechanically retentive ceramic brackets. Am J Orthod Dentofacial Orthop. 2008;134:181e1-7. 26- Underwood ML, Rawls HR, Zimmerman BF. Clinical evaluation of a fluoride-exchanging resin as an orthodontic adhesive. Am J Orthod Dentofacial Orthop. 1989;96:93-9.
27- Valandro LF, Della Bona A, Bottino MA, Neisser MP. The effect of ceramic surface treatment on bonding to densely sintered alumina ceramic. J Prosthet Dent. 2005;93:253-9.

28- Van Noort R, Cardew GE, Howard IC, Noroozi S. The effect of local interfacial geometry on the measurement of the tensile bond strength to dentin. J Dent Res. 1991;70:889-93.

29- Versluis A, Tantbirojn D, Douglas WH. Why do shear bond tests pull out dentin? J Dent Res. 1997;76:1298-307.

30- Wegner SM, Kern M. Long-term resin bond strength to zirconia ceramic. J Adhes Dent. 2000;2:139-47. 